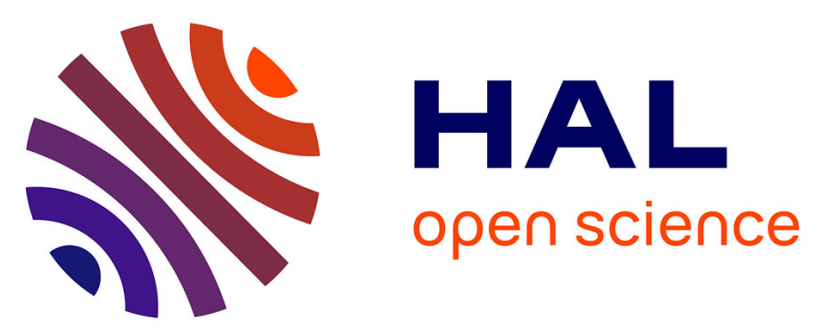

\title{
Robust Ultrasound-Based Visual Servoing for Beating Heart Intracardiac Surgery
}

Marie-Aude Vitrani, Hubert Mitterhofer, Nicolas Bonnet, Guillaume Morel

\section{To cite this version:}

Marie-Aude Vitrani, Hubert Mitterhofer, Nicolas Bonnet, Guillaume Morel. Robust UltrasoundBased Visual Servoing for Beating Heart Intracardiac Surgery. 2007, 10.1109/ROBOT.2007.363931 . hal-01170711

\section{HAL Id: hal-01170711 \\ https://hal.sorbonne-universite.fr/hal-01170711}

Submitted on 2 Jul 2015

HAL is a multi-disciplinary open access archive for the deposit and dissemination of scientific research documents, whether they are published or not. The documents may come from teaching and research institutions in France or abroad, or from public or private research centers.
L'archive ouverte pluridisciplinaire HAL, est destinée au dépôt et à la diffusion de documents scientifiques de niveau recherche, publiés ou non, émanant des établissements d'enseignement et de recherche français ou étrangers, des laboratoires publics ou privés. 


\section{Robust Ultrasound-Based Visual Servoing for Beating Heart Intracardiac Surgery}

\author{
Marie-Aude Vitrani, Hubert Mitterhofer and \\ Guillaume Morel \\ University Pierre et Marie Curie - Paris 6 \\ Laboratoire de Robotique de Paris \\ 18 route du panorama, \\ 92265 Fontenay-aux-Roses, France \\ \{vitrani, morel\}@robot.jussieu.fr
}

\author{
Nicolas Bonnet \\ University Pierre et Marie Curie - Paris 6 \\ Pitié-Salpêtrière Hospital \\ Cardiac Surgery Service \\ 47-83 boulevard de l'Hôpital \\ 75013 Paris, France \\ nicolas.bonnetepsl.ap-hop-paris.fr
}

\begin{abstract}
This paper presents a robust visual servoing approach for automatic guidance of an instrument. The visual sensor is an ultrasound probe that observes an instrument which is inserted into the beating heart of a patient and manipulated by a robot. The present paper provides stability analysis, robustification of the control law and an in vivo experiment.
\end{abstract}

\section{INTRODUCTION}

Ultrasound imaging systems are mainly used for non operative observation of inner organs. However, they can also be employed for intervention procedures, where the surgeon moves an instrument inside a patient while observing the motion of the instrument with an outer ultrasound probe. This requires high skills for coordinating the hands holding the instrument and the probe. In fact, the ultrasound image gives only a $2 \mathrm{D}$ cross-section of the $3 \mathrm{D}$ operating region, containing no depth information. Therefore, manual ultrasound guided interventions are limited to simple tasks, such as puncture using a needle [1].

Within this context, robotic systems are being developed in order to accomplish ultrasound image-based guidance in a more performing way than manual procedures. More and more interventional systems exploit both robotics and medical imaging. They can be divided into three categories, depending on the mode of cooperation between the robot and the imaging device: via the surgeon, via $3 \mathrm{D}$ reconstruction or via visual servoing.

Cooperation via the surgeon: for this kind of systems, the images and the robot are two separate tools used simultaneously but independently by the surgeon; in particular, the robot never uses the information provided by the imaging system, neither directly nor indirectly. Typical examples are telemanipulated systems and some cobotic systems.

The teleoperation systems allow remote examinations. In [2], [3], [4], telemanipulators holding an ultrasound probe for the remote diagnosis are proposed. In [5], a system is proposed where the robot and the surgeon simultaneously hold an ultrasound probe. The comanipulation is used so that the surgeon can position the probe in an intuitive way. The robot's assistance allows to realize the desired displacement by guaranteeing a constant limited effort on the patient skin.
In all these systems, the image is simply used to provide a view of the patient and/or instruments to the surgeon, exactly as for manual interventions. The image is never used for automatic guidance purposes.

Cooperation via 3D reconstruction: in this second class of systems, pre-or per-operative images are processed in order to reconstruct $3 \mathrm{D}$ information which is then used by the robot. In [6], two robots collaborate. A first robot handles the ultrasound probe. Thanks to a localization of the anatomical target in the image and geometrical model, a second robot, handling a needle, is commanded towards the computed 3D position. In vitro tests emphasize a better accuracy than with manual procedures. The system proposed by [7] allows to carry out a biopsy of the prostate. The prostate $3 \mathrm{D}$ model is reconstructed using the ultrasound images. Thus the robot is fed with the 3D model in order to compute the trajectory. The tests on dead bodies showed a final positioning error of about $2,5 \mathrm{~mm}$. Some systems also use the images to perform, in real time, the 3D reconstruction of the desired position instead of establishing a patient model from preoperative images, [8], [9]. In these systems, the target is detected and tracked in the images. Their 3D position can then be calculated in a robot coordinate frame. The main limit of the 3D reconstruction is that geometrical errors are cumulated due to the multiple devices used for localization which results in important errors in the final robot positioning.

Cooperation via visual servoing: in this last category, the positioning error is measured directly in the image and is used to calculate the robot displacement towards the desired image position. In [10], the control is shared between the surgeon and a visual servoing loop, which is used to compensate for the physiological movements. In [11] visual servoing is used to position an ultrasound probe with respect to a phantom which geometry is known. The system is used to establish a calibration procedure for 3D ultrasound probes. Finally, a system for guiding a needle by visual servoing is proposed in [12]. It consists of an ultrasound probe and a needle manipulator with two degrees of freedom. The needle is mechanically forced to remain in the ultrasonic plane. Its orientation and its penetration are controlled automatically by a visual servoing loop. However, this research treats only 